\title{
Variação e funcionalidade*
}

\author{
Anthony Julius Naro \\ Universidade Federal do Rio de Janeiro
}

\section{Abstract}

Both functional and non-functional variation exist on a large scale. A typically non-functional phenomenon is subject/verb concord, where plural markers are used more often precisely in those environments in which they are unnecessary from the point of view of communicating meaning, such as when the subject and verb are adjacent. On the other hand, the use of realized versus zero subject pronouns is fully functional: such pronouns tend to be used more frequently in environments in which their absence would lead to ambiguity in interpretation on the discourse level. Non-functional variation is a characteristic of phenomena that are in an advanced stage of diachronic evolution, near the end of the functional cycle. Functional variation can be found near the beginning of the cycle. In this regard, variable agreement has been occurring for several centuries, while the marked increase in frequency of use of subject pronouns is very recent. 


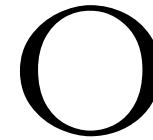

s mais de trinta anos de pesquisa sobre variação lingüística desde as primeiras investigações de William Labov sobre o inglês americano têm demonstrado que a variação no uso da língua é um fenômeno regular, sujeito a restrições de natureza estrutural, internas ao sistema lingüístico, e social, externas a esse sistema. Não pode mais existir a menor dúvida sobre a natureza não aleatória da variação lingüística.

As pesquisas iniciais no campo da variação eram principalmente a respeito de fenômenos fonológicos ou fonéticos, a exemplo da realização velar ou dental da consoante final do sufixo do gerúndio -ing em inglês em palavras do tipo de walking 'andando'. A este nível todas as variantes comunicam o mesmo valor semântico denotativo, e o papel da variação na comunicação lingüística não parecia um problema relevante. Mais tarde, entretanto, a semântica entrou em cena com pesquisas sobre o uso variável das vozes ativa e passiva, dos modos subjuntivo e indicativo, de diversas maneiras de expressar tempos verbais como o passado ou o futuro, etc.

Inicialmente o debate se concentrou em torno da questão da legitimidade de qualquer estudo em que o nível semântico entrasse em jogo. Creio que hoje em dia não existe mais esta dúvida: podemos estudar fenômenos que implicam diferenças de sentido entre as variantes se levarmos em consideração este fator, como qualquer outro fator relevante.

Atualmente a questão mais intrigante em relação à variação é o seu possível efeito sobre a comunicação durante o processo de mudança e uso real da língua. Este efeito ultrapassa o nível da semântica lexical e clausal, atingindo o nível do discurso. A pergunta que se coloca naturalmente é se a variação contribui para o sucesso da transmissão comunicativa através da língua. Em princípio não 
existe nenhuma razão para acreditar que a resposta será positiva a variação poderia, pela sua própria natureza não-categórica, atrapalhar ou dificultar a comunicação.

Em seu livro Principles of linguistic change, Labov (1994) dedica os últimos três capítulos justamente a esta área problemática. O título do primeiro destes capítulos - "The overestimation of functionalism" - já indica a conclusão a que o autor chegou.

Para Labov, a variação seria funcional na medida em que preservasse a comunicação explícita da informação, no sentido de favorecer a realização de uma variante explícita sob circunstâncias em que, de outra maneira, um determinado elemento semântico ficaria sem expressão na forma sonora. Com relação ao morfema, por exemplo, o autor cita os estudos de Gregory Guy (1980) sobre o apagamento dos segmentos $-t$ e $-d$ em final de palavra em inglês. Num primeiro momento, esta variação parecia funcional porque o segmento é conservado com maior freqüência quando marca o tempo passado do verbo regular (exemplo: walked 'andado') do que quando constitui mero material fônico não distintivo dentro de uma palavra (exemplo: fact 'fato'). Guy estudou o caso dos particípios regulares (exemplo: have walked 'tem andado'), em que a oclusiva é redundante porque o auxiliar have 'ter' seria suficiente para marcar o tempo verbal. Mesmo sendo redundante, a oclusiva do particípio é conservada com a mesma eficiência da do passado regular. A preservação do sentido não pode explicar este resultado. Se o caso de $-t,-d$ em inglês não contradiz a hipótese funcional em nível morfológico, ele também não fornece evidência a seu favor.

O golpe final ao nível morfológico vem do apagamento variável de $-s$ e $-m$ em português e espanhol. Todos os estudos concordam na conclusão de que estes segmentos são apagados com maior freqüência justamente quando marcam o plural em nomes e verbos (exemplos: pessoas, comem). São conservados com mais eficiência quando mero material não-distintivo (exemplos: pires, comum). Este resultado é anti-funcional porque o segmento desaparece justamente quando tem um papel funcional a desempenhar: a comunicação do sentido plural. 
Shana Poplack (1980) fez um estudo detalhado de vários tipos de fatores que regem a variação do $-s$ em espanhol. Entre outros efeitos, Poplack mostrou que este morfema nominal de plural se faz presente quando não existem outras marcas de plural no contexto. Este efeito é funcional porque o segmento se mantém quando necessário para a preservação do sentido, mas ele é estatisticamente mais fraco do que outros fatores não funcionais, tais como status morfológico, acima mencionado.

Os estudos que eu mesmo fiz em colaboração com Marta Scherre (Scherre \& Naro 1991) confirmam a natureza predominantemente não funcional da concordância. Mostramos que no caso de cadeias de verbos com o mesmo sujeito no discurso, a marcação de um determinado verbo na cadeia depende estatisticamente da marcação do verbo anterior de maneira obviamente não funcional: a um verbo marcado segue preferencialmente outro marcado e a um verbo não-marcado segue preferencialmente outro não-marcado. A marca parece uma mera repetição mecânica, desprovida de qualquer efeito comunicativo. O número semântico do sujeito cede à forma morfológica anterior o papel de determinador da variante preferencial. Este efeito anti-funcional pode ser apreciado no seguinte exemplo:

...ELEs falam que vai expulsar os outros do morro. Aí, fala: "Você não pode mais subir o morro!". Aí, a pessoa tem que obedecer e não pode mais subir mesmo, né? Porque subir, morre. Que eles fala que vai matar, e mata mesmo.

Depois do primeiro verbo da cadeia, sublinhado, todas as ocorrências seguintes, em itálico, estão sem a marca. Podemos até duvidar do sentido real. Será que na primeira frase o falante quis dizer "eles falam que eles vão expulsar os outros do morro" ou "eles falam que alguém vai expulsar os outros do morro"? Só o contexto extra-lingüístico poderá esclarecer a dúvida. O material lingüístico realmente usado não ajuda na determinação deste traço semântico.

No tipo de uso discutido acima, as variantes usadas, na maioria das vezes, não preservam a expressão do sentido. Sem dúvida, estes 
fenômenos variáveis se mostram predominantemente anti-funcionais, no sentido de que podem dificultar a transmissão de informação, ou, pelo menos, não-funcionais, no sentido de não ajudarem na efetivação deste processo. Entretanto, os fenômenos arrolados são de uma determinada fase no desenvolvimento histórico das línguas: são processos antigos em que as forças que determinaram o início do processo de mudança e variação já não estão mais em evidência. Em termos sociolingüísticos, são casos de variação estável há muito tempo, ou nos quais se constatam movimentos em diferentes direções em diversos subgrupos da população. Este fato é relevante porque as línguas seguem um trajeto no tempo, conhecido como o ciclo funcional, em que nem todas as etapas são igualmente eficientes do ponto de vista do exercício efetivo da funcionalidade.

Nos seus estudos pioneiros sobre o ciclo funcional no desenvolvimento histórico das línguas, Gillian Sankoff (1980) alertou para o fato de que inovações com funções claras e bem marcadas no discurso costumam, com o decorrer do tempo, sofrer processos de regularização gramatical e enfraquecimento sonoro que levam fatalmente à perda da sua funcionalidade (Sankoff 1980, p.270). Ela exemplifca com a história da inserção de pronomes depois de sujeitos nominais em Tok Pisin, língua falada na Nova Guiné e baseada em parte no inglês. Por volta do final do século 19 o pronome pleonástico começou a ser usado para marcar sujeitos em contextos discursivos específicos, tais como mudança de tópico e para relacionar sujeitos complexos ao verbo. Considere o seguinte exemplo de mudança de tópico:

Juiz (Inglês): - Did you talk to captain at Townsville? 'Você falou com capitão em Townsville?'

Testemunha (Tok Pisin): - No; Jack HE talked. 'Não; Jack ELE falou.'

Neste primeiro momento, a freqüencia de uso de he era baixa. Já no início do século 20, o uso do pronome começou a se generalizar para outros contextos, não mais funcionalmente motivados, e a sua frequência de uso aumentou muito, atingindo o nível de $70 \%$ por 
volta de 1940. Neste estágio be perde sua autonomia e é fonologicamente reduzido ao clítico $i$ - em posição pré-verbal. Trata-se neste momento de uma mera partícula gramatical associada ao predicado, sem qualquer utilidade funcional. Concomitantemente a esta perda da funcionalidade de he, começa a ser utilizado nesta época outro dispositivo para a antiga função de $h e-$ a forma $e m$, derivado do inglês him, que, exatamente como he no século anterior, também começa o ciclo funcional com baixa freqüência de uso, funcionalmente transparente. Um exemplo de mudança de tópico nesta segunda leva de funcionalidade transparente é:

Mitufela sutim, givim long kandari, Bandarap. Bandarap, EM I-kukim. 'Nós dois atiramos nele, e o demos ao irmão da minha mãe, Bandarap. Bandarap, ELE o cozinhou.

Note-se que a nova forma funcional em é usada junto com a partícula gramatical $i$-, descende direto do antigo $b e$.

Nas décadas seguintes, a partícula $i$-reverte a sua tendência anterior ao uso mais freqüente e começa a cair, até chegar ao nível de meros 20\% a 30\% por volta de 1970, devido à introdução de regras morfofonêmicas que a apagam em certos contextos. Enquanto isso, em vai aumentando seu uso, provavelmente no mesmo caminho em direção à perda de funcionalidade já trilhado por he.

Em diversas obras, Talmy Givón (1995, p. 60) tem destacado o ciclo funcional, esquematizado como se segue:

$$
\text { discurso } \longrightarrow \text { sintaxe } \longrightarrow \text { morfologia } \longrightarrow \text { zero }
$$

Na fase de Tok Pisin da década de 70, a marca de predicado $i$ - estava ainda na fase morfossintática, mas já a caminho de zero, a fase final do ciclo, enquanto em estava ainda na fase discursiva. Segundo Givón, a plena funcionalidade existe apenas em algum ponto medial do ciclo. No final do ciclo, com a erosão fonética, a situação é de pobreza de marca, enquanto no início existiria um excesso de marca. Esta visão é consistente com o estudo de Sankoff quanto ao final do ciclo, em que o clítico $i$ - já está sujeito ao apa- 
gamento morfofonêmico. Entretanto, Sankoff consegue identificar motivações funcionais mesmo com freqüências muito baixas de uso.

Como observamos anteriormente, em seu livro Labov examinou fenômenos variáveis que se encontram no FINAL DO CICLO FUNCIONAL de Sankoff. Portanto, não é de se surpreender que ele não tenha achado aí muita funcionalidade. Acrescenta-se a isto o fato de Labov ter levado em consideração apenas a PRESERVAÇÃo do sentido lexical e gramatical nos níveis fonológico e morfológico através do uso de codificação material. Esta visão de funcionalidade nos parece muito estreita. Em primeiro lugar, a simples COMUNICAÇão de sentido, mesmo sendo redundante, pode ser considerada funcional já que todo o processo de uso da língua é altamente redundante. A redundância faz parte do perfil próprio do uso lingüístico. Em segundo lugar, a comunicação de sentidos discursivos, bem como o uso de estratégias diferentes da codificação formal, não foram examinados por Labov.

A plena funcionalidade existe em diversas áreas de variação sincrônica estudadas por pesquisadores brasileiros. Por exemplo, Cecília Mollica (1996) examinou o uso das preposições em, a, e para com o verbo de movimento ir e descobriu que o uso de em tem a função de reforçar o traço definido do referente locativo. Assim, o contexto mais típico de em é:

A gente ia No Carrefour,

em que existe o artigo definido e o locativo é um lugar cercado, com entrada definida.

Da mesma forma, em seu estudo sobre a cópia pronominal em cláusulas relativas, Mollica (1981) apontou a função do pronome como referencializador do seu antecedente. Neste caso o uso típico é:

Eu tenho uma colega que ela é doidinha por lá,

em que a referência de uma colega se torna definida com a presença do pronome ela.

No estudo do chamado (DE)Queísmo, Mollica (1995) notou a função do de como distanciador do falante em relação ao conteúdo 
da cláusula encaixada, bem como sua função de recuperar a conexão entre a cláusula principal e a encaixada. Um exemplo típico seria:

Eu poderia provar para o povo DE QUE houve fraude nas eleições passadas.

Não pode existir nenhuma dúvida de que em todos estes fenômenos estudados por Mollica o uso variável está contribuindo de forma cabal para o sucesso da comunicação.

Muitos outros estudos sobre o português do Brasil também confirmam a funcionalidade da variação. Podemos citar as pesquisas de Vera Paredes (1993) sobre o uso variável de zero ou pronome na posição de sujeito. Neste caso, os resultados de três variáveis ambigüidade, ênfase e conectividade discursiva - mostram que o pronome explícito é mais usado justamente quando sua referência é menos previsível. Um caso típico seria:

Mamãe me disse que você está com alergia,

em que a falta do pronome traria confusão ao nível referencial.

Convém também mencionar os estudos de Giselle Machline de Oliveira e Silva (1996) sobre o uso do artigo definido diante de possessivo e de patronímico. Através da análise de um conjunto de variáveis do tipo personagem não conhecida $v s$ personagem de domínio público, entidade nova vs não-nova, Oliveira e Silva mostrou que o artigo é usado mais quando existe uma maior necessidade de identificação do referente.

Nem todos os fenômenos acima mencionados têm uma localização clara no meio do ciclo funcional. Considere-se o caso do uso variável do sujeito pronominal estudado por Paredes. Esta é seguramente uma variação secular em português ou até milenar se levarmos em conta as línguas das quais deriva. Entretanto, o recente aumento na sua freqüência de uso no Brasil a partir do século 19 salta aos olhos e tem levado alguns estudiosos a postularem a existência de uma mudança tipológica na língua. Deste ponto de vista, não se trataria de uma variação estável atualmente. O aumento do (de) 
queísmo e do uso da preposição em com o verbo de movimento ir parecem também ser bem recentes.

Todos os fenômenos variáveis do português vistos até aqui são plenamente funcionais no momento atual, no sentido de que a variante favorecida em determinado contexto fornece elementos para uma compreensão correta da mensagem dentro daquele contexto. No estágio em que se encontram no momento, estas variações não deixam prever uma fase futura em que a variante preferida será zero. Pelo contrário, são todos casos nas etapas iniciais do ciclo, em que uma variante explícita está em vias de se estabelecer, exatamente como no caso da inserção de pronomes depois de sujeitos nominais em Tok Pisin. Só o tempo dirá se tais variantes deverão se tornar zero em algum momento do futuro.

Outro fenômeno que parece estar bem no início do ciclo é o uso variável das desinências verbais -O (zero), da terceira pessoa do singular, e -mos, da primeira pessoal do plural, com as formas pronominais a gente e nós para expressar a primeira pessoa do plural. Como sabemos, o português-padrão prefere o uso de -mos com nós e de -O (zero) com a gente. Entretanto a forma com -mos (exemplo: falamos) é ambígua entre os tempos presente e passado. A pesquisa de que participei sobre este assunto, levada a cabo por Edair Görski e Eulália Fernandes (Naro, Görski \& Fernandes 1983), demonstrou na década passada que as crianças estavam tendendo a reservar o uso de -mos para o tempo passado, independentemente do sujeito ser nós ou a gente. Os adultos não exibiam esta preferência claramente funcional. Se esta tendência se confirmar no futuro, teremos um caso em que uma variação funcional ao nível morfológico se gramaticaliza. No momento, o eventual trajeto para zero não se vislumbra no horizonte gramatical, a não ser que a desinência -mos acabe caindo junto com todas as outras desinências verbais.

Outro caso aparente de estabilização é a escolha entre a ordem canônica sujeito/verbo e a chamada variante "inversa" verbo/sujeito. Este fenômeno segue tão de perto o critério funcional que dificilmente podemos falar de variação. Com efeito, a forma verbo/sujeito é usada de maneira quase categórica para indicar circunstâncias fora 
do fluxo principal de informação, segundo resultados de uma pesquisa que fiz em colaboração com Sebastião Josué Votre (Naro \& Votre 1987). O caso típico de VS é:

De noite eu ia para ali perto do - na rua Riachuelo, né? TinHa um DEPósito de Jornal O Dia. Comprava o jornal, ia para Copacabana vender dentro dos ônibus. Aí, quando dava assim três e meia, mais ou menos, acabava o jornal. Aí, quatro horas pegava o trem para Japeri.

No trecho citado acima, o fluxo informacional principal é a respeito de ' $e u$ ', o falante. Este fluxo se interrompe duas vezes - para explicar o que havia do interesse do falante na Rua do Riachuelo, e para relatar um evento exterior ao falante. Ambos os desvios do plano da figura para o do fundo estão na ordem verbo/sujeito.

Da preferência claramente funcional da ordem verbo/sujeito para trechos de fundo segue-se toda uma série de conseqüências distribucionais e sintáticas, inclusive a quase total exclusão de verbos transitivos em VS. Temos então um caso de variação na ordenação de palavras, de base claramente funcional, que já se gramaticalizou no nível sintático na forma de uma nova construção gramatical. Ainda mais que no caso de -mos, não se deixa entrever um futuro caminho em direção a zero.

Em resumo, existe evidência abundante sobre a natureza plenamente funcional de um bom número de fenômenos variáveis em português. Com isso queremos dizer que, nestes casos, os falantes usam mais certas variantes em contextos em que o uso da variante em questão, e não outra variante, colabora para transmitir um determinado sentido em nível semântico ou discursivo. Também temos evidências a favor da gramaticalização da variação nos níveis morfológico e sintático. Reconhecemos, entretanto, que existem casos em que a variação é puramente mecânica, sem qualquer efeito funcional, bem como casos em que os dois tipos estão em concorrência. Segundo a noção de ciclo funcional sugerida por Gillian Sankoff, a variação funcionalmente motivada deve ser encontrada em algum trecho não-final do ciclo, enquanto a variação mecanica- 
mente regida poderá ser encontrada no final do ciclo. A evidência que temos até o momento é consistente com esta idéia, mas precisamos refinar a noção de ciclo funcional de maneira a poder localizar nela com critérios mais rigorosos os fenômenos variáveis e em vias de gramaticalização.

\section{NOTA}

* Esta é uma versão revista do texto da minha conferência "A funcionalidade da variação lingüística", apresentada durante o I Encontro de Variação Lingüística do Cone Sul, em Porto Alegre, 2 a 4 de setembro de 1996.

\section{REFERÊNCIAS BIBLIOGRÁFICAS}

GIVÓN, Talmy. Functionalism and grammar. Amsterdam: John Benjamins, 1995.

GUY, Gregory. Variation in the group and the individual: The case of final stop deletion. In Labov 1980, p.1-36, 1980.

LABOV, William (org). Locating language in time and space. New York: Academic, 1980.

. Principles of linguistic change: internal factors. Oxford: Blackwell, 1994.

MOLLICA, Cecilia. La 'copie' dans les constructions relatives en portugais. In Variation omnibus, p.329-334. Carbondale: Linguistic Research, Inc, 1981. . (De) Que falamos?. Rio de Janeiro: Tempo Brasileiro, 1995.

A regência variável do verbo ir de movimento. In Oliveira e Silva e Scherre (orgs.) 1996, p.147-168.

NARO, Anthony J., Edair Görski \& Eulália Fernandes. Uma mudança lingüística em curso: a concordância com o sujeito nós / a gente. Trabalho apresentado durante o Seminário sobre Variação em Sintaxe, Universidade Federal do Rio de Janeiro, 1983.

NARO, Anthony J. \& Sebastião J. Votre. Emerging syntax as an effect of discourse. A aparecer em Probus,1987.

. Mecanismos funcionais do uso lingüístico. DELTA 5:169-184, 1989.

OLIVEIRA e SILVA, Giselle Machline de. Realização facultativa do artigo definido diante de possessivo e de patronímico. In Oliveira e Silva e Scherre (orgs.) 1996, p.119-146. 
OLIVEIRA e SILVA, Giselle Machline de e Maria Marta Pereira Scherre (orgs.). Padrões sociolingüísticos. Rio de Janeiro: Tempo Brasileiro, 1996.

PAREDES Silva, Vera Lúcia. Subject omission and functional compensation: evidence from written Brazilian Portuguese. In Language variation and change 5:35-50, 1993.

POPLACK, Shana. The notion of plural in Puerto Rican Spanish: competing motivations on /s / deletion. In Labov 1980, p.55-68.

SANKOFF, Gillian. Variability and explanation in language and culture: cliticization in New Guinea Tok Pisin. In Gillian Sankoff, The social life of language, 1980, p.257-270. Philadelphia: University of Pennsylvania Press.

SCHERRE, Maria Marta Pereira \& Anthony J. Naro. Marking in discourse: "Birds of a feather". In Language Variation and Change 3:23-32, 1991. 